to the amniote line, has a strikingly similar stapes ${ }^{8}$. Both Greererpeton and Pholiderpeton lack otic notches.

Clack now shows ${ }^{3}$ that the stapes of the much earlier Acanthostega is of the same type. Yet Acanthostega also appears to have otic notches. She suggests, however, that these did not hold tympana, but that each formed the margin of an open spiracle. She further suggests that the stapes was concerned with pumping movements to draw in either air or water through the spiracle for respiration. In fish where the spiracle remains open, notably in skates and rays, the hyomandibula helps to pump water into the buccal cavity; the water is then expelled through the other gill slits. Clack suggests that the stapes of Acanthostega, the homologue of the hyomandibula, also had this respiratory function, but probably to ventilate the lungs.

If Clack and her colleagues had not recovered stapes associated with skull material, one might have predicted that the function of Acanthostega's stapes was to conduct sound from a tympanum held in the otic notch. Given that three unre- lated tetrapod groups are known to have this arrangement, it would have been reasonable to suppose that this was the primitive tetrapod condition and thus would be found in Acanthostega. The lack of otic notches, and the massive stapes found in Greererpeton and Pholiderpeton, could then have been seen as secondary features. The discovery in Acanthostega of both massive stapes and otic notches thus forces a re-evaluation of the primitive tetrapod condition that will inevitably affect our ideas about tetrapod phylogeny.

Alec L. Panchen is in the Department of Biology, University of Newcastle upon Tyne, Newcastle upon Tyne NE1 7RU, UK.

\section{Panchen, A.L. Nature 333, 704 (1988).}

2. Janvik, E. Basic Structure and Evolution of Vertebrates (Academic, London, 1980).

3. Clack, J.A. Nature 342, 425-427 (1989).

4. Goodrich, E.S. Studies on the Structure and Development of Vertebrates (Macmillan, London, 1930).

5. Kemp, T.S. Mammat-like Reptiles and the Origin of Mammals (Academic, London, 1982)

6. Lombard, R.E. \& Bolt, J.R. Biol. J. Linn. Soc. 11, 19-76 (1979)

7. Smithson, T.R. Zool. J. Linn. Soc. 76, 29-90 (1982) 8. Clack, J.A. Zool. J. Linn. Soc. 79, 121-148 (1983)

\title{
AMAZON DEFORESTATION-
}

\section{Predicting climate effects}

\section{Robert E. Dickinson}

FEARS that global and local meteorological balances might be upset by the deforestation of the Amazon have made the destruction of the rainforest a matter of wide public concern. Elsewhere in this issue (Nature 342, 411-413; 1989), J. Lean and D. Warrilow describe detailed computer simulations that reveal the impact that might be expected if large tracts of rainforest are replaced by pasture. Most strikingly, they find that rainfall in the region could be dramatically reduced.

The role of tropical forests in the global climate system has long been a subject of speculation. Brazilian studies of the hydrological balance in the Amazon have done much to foster the debate over the past decade. Joint UK-Brazilian micrometeorological investigations are now giving us a much clearer view of the balances of energy and water in and above the forest canopy. But it is only with detailed climate models, such as those used by Lean and Warrilow and also by C. Nobre, J. Shukla and P. Sellers (submitted to Science), including representations of the role of vegetation in the water and surface-energy balances, that we can make quantitative estimates of the regional and global changes that may follow extensive deforestation.

As well as predicting a 20 per cent decrease in rainfall over the Amazon region, Lean and Warrilow suggest that the local climate will become warmer and that evapo-transpiration will be reduced. My earlier study with A. HendersonSellers and M.F. Wilson (see $Q . J l R$. met. Soc. 114, 439-462; 1988), using the National Center for Atmospheric Research community climate model (CCM), also indicated that warming and reduction of evapo-transpiration on a similar scale would follow deforestation, but the model hydrological cycle was too 'noisy' to establish any clear indication of

\section{0 years ago}

Mirage in the South American Pampas

I was staying in the Pampas of the Argentine Republic, near Melincue, a small town of the Provence of Santa Fe, from September 1888 to March 1889. During my stay I had the opportunity of observing certain mirage phenomena. To illustrate my observations I had drawn eight diagrams; but, for the purpose of insertion in Nature, I have been obliged to reduce these. Hence I fear that my descriptions may not be as clear as I should wish.

\section{The Winter Mirage.}

I saw this mirage several times, always about sunrise and after a frost. There would be, for example, just below, or on the edge of the line $(\alpha)$, a cow. This I will call the "first cow," or the "original cow." Just below or on the line $(\beta)$, vertically above the first cow, and, like it, erect, would be a second cow, a repetition of the first. And often, above this again, below or on the line $(\gamma)$, would be a third cow, also erect. changes in rainfall.

Regional rainfall in the Amazon is highly variable, in both space and time, owing to variations in tropical ocean temperatures. Until climate models can reproduce this variability, projections of changes induced by altered land use will be greeted with scepticism. The hydrological cycle is regarded by many as the weakest component in climate models. The main difference between our earlier study and Lean and Warrilow's is in the numerical treatment of the spatial dimensions, their approach avoiding hydrological difficulties associated with ours. The link the new study seems to have established between rainfall and tropical forests is one of the strongest of its kind yet modelled.

The suggestion of this link increases the urgency with which related questions must be addressed. How do the rainfall anomalies affect weather patterns in the Northern Hemisphere? By analogy with the El Niño-Southern Oscillation phenomena, large-wavelength, transverse 'Rossby' waves in the atmosphere might propagate long-range effects. Will the accompanying changes in ocean temperatures amplify or mitigate the predicted effects? It will be important to find out whether climate changes due to deforestation will act through the forest ecosystem to accelerate the current decline. It may be that the tropical forests are sufficiently stable that they will grow back once human intervention ceases.

The interest in the rainforest reminds us of the other effect of vegetation on climate. Vegetation is a reservoir for carbon that annually exchanges with the atmosphere an order of magnitude more $\mathrm{CO}_{2}$ than is added by human activity. The loss of the tropical forests is recognized as adding significantly to the increases in atmospheric $\mathrm{CO}_{2}$. As the political will grows to prevent such increases, it is

Sometimes there were confused images hanging from the second cow and joining other confused images piled on the first cow; sometimes the first cow was clear of images, while

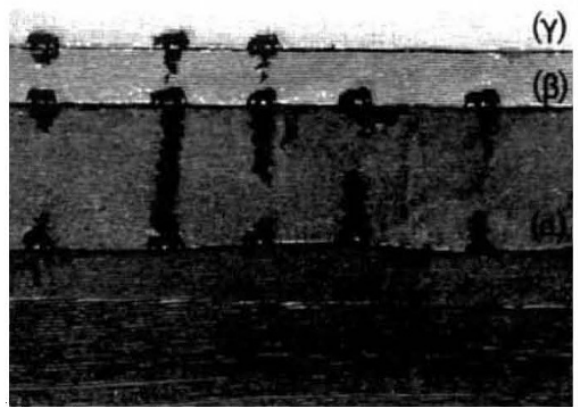

they hung down from the second cow; sometimes the second cow was near, and there were images piled on the first.

The mirage lasted until about an hour and a quarter after sunrise.

W. LARDEN

From Nature XLI, 69-71; November 1889. 